CIC. Cuadernos de Información y Comunicación ISSN: 1135-7791

http://dx.doi.org/10.5209/CIYC.55976

\title{
¿Es posible el periodismo al margen del discurso periodístico? Tensiones entre medios y ciudadanos por la información
}

\author{
Santiago Peribañez ${ }^{1}$
}

Enviado: 20 de abril de 2017 / Aceptado: 25 de abril de 2017

\begin{abstract}
La comunicación digital ha desarrollado nuevas vías de información para la ciudadanía, que cuenta con un rico abanico de posibilidades más allá de los medios tradicionales. La consolidación de las herramientas de la web 2.0 ha popularizado la elaboración y consumo de los contenidos generados por el usuario (UGC), que en muchos casos supone una vía de información más directa y legitimada que las cabeceras convencionales. La respuesta de la industria periodística ha imitado el lenguaje de estos nuevos medios, incorporando memes y montajes humorísticos en su discurso, sin asumir la crítica a la calidad que suponen estos espacios abiertos a la ciudadanía. La convivencia entre ambos discursos es especialmente evidente en el caso de la información deportiva, objeto de este estudio, puesto que dispone de una audiencia bien formada y muy participativa. Por eso, es una buena muestra del futuro que quizás espere a la comunicación actual.
\end{abstract}

Palabas clave: Comunicación digital; prosumidor; redes sociales; periodismo; memes; User-Generated Content; discursos ciudadanos

\section{[en] Is journalism possible outside the journalistic discourse? Tensions between media and citizens for information}

Abstract. Digital communication has developed new channels of information for citizens, who have a rich range of possibilities beyond traditional media. The consolidation of web 2.0 tools has popularized the elaboration and consumption of user generated content (UGC), which for many readers is a way of information with more legitimacy than conventional media. The response of the journalistic industry has imitated the language of these new media, incorporating memes and humorous montages in its discourse, without assuming the criticism to its quality that suppose these spaces open to the citizenship. The coexistence between both discourses is especially evident in the case of sports information, object of this study, since it has a well-formed and very participative audience. Therefore, it is a good example of the future that perhaps awaits the current communication.

Keywords: Digital communication; prosumer; social networks; journalism;memes; User Generated Content; citizen discourse

Sumario. 1. Estado de la cuestión. 2. Análisis. 3.1. Escena 1: La exuberancia del líder. 3.2. Escena 2: En busca de la chilena perdida. 4.Discusión. 5. Bibliografía.

Cómo citar: Peribañez, S. (2017). ¿Es posible el periodismo al margen del discurso periodístico? Tensiones entre medios y ciudadanos por la información, en CIC. Cuadernos de Información y Comunicación 22, 223-246.

Universidad Complutense de Madrid
Email: santiagoperibanez@gmail.com 


\section{Estado de la cuestión}

Las nuevas tecnologías han invadido casi cada rincón de nuestras vidas, alterando por completo el modo en que se producía y se consumía la información. Diez años después, ahora estamos en condiciones de empezar a valorar los cambios prometidos por el periodismo ciudadano: enfoques más rigurosos, temas más serios, las audiencias como supervisores de los periodistas... La propia estructura de las noticias se ha visto transformada por completo con el periodismo en internet, fragmentando programas en vídeos más cortos (y virales), además de conectar reportajes diferentes mediante enlaces, alterando las estructuras mentales y textuales de la información [vid la revisión de Aladro, 2011]. Todos estos cambios son caras de un mismo cubo; analizadas por separado obtendremos un resultado parcial.

La llegada de Internet puso contra las cuerdas a una industria periodística ya rendida tiempo atrás, sin adaptarse a los cambios demandados por las nuevas generaciones. El desarrollo digital vino a agravar la crisis estructural del periodismo que, sumada a la crisis económica, ha convertido al cuarto poder en una búsqueda continua de espectáculos y sucesos llamativos, "un sistema de remezcla de la información proporcionada desde el exterior, elaborada por el sistema de relaciones públicas (...) El cambio de la información al infoentretenimiento ha sido abrazado por los mismos periodistas, dificultando la publicación de los reportajes complejos" (Lovink y Riemens, 2011: 141-142).

El desarrollado sistema de métricas permite a la empresa conocer no solo las noticias más leídas por la población, sino la duración de estas y su actividad. Nunca como ahora ha sido tan evidente la separación entre lo que los medios ofrecen y la audiencia quiere leer: "independientemente de la influencia recíproca entre periodistas y lectores, hay una trayectoria claramente divergente en las preferencias de lectores y periodistas [...] hasta un 19\% de puntos porcentuales" (Boczkowski, 2013: 53). Esta separación entre la oferta y las necesidades informativas llevará a una parte de la población a buscar (y crear) otros canales de información.

En este entorno, los patrones de consumo se desdibujan y la población no solo recurre a medios de información sino que acude con asiduidad a contenidos generados por los usuarios (UGC). De hecho, los jóvenes (20-35 años) ya confían más en la información recibida por estos canales que en la transmitida por periodistas [IPSOS, 2014: 5]. Por ejemplo, un 65\% confía en las conversaciones a través de correo o redes sociales, mientras que un $48 \%$ considera los blogs como una fuente válida. Este porcentaje cae hasta el $44 \%$ en el caso de los periódicos y revistas impresas, el porcentaje más alto dentro de los medios periodísticos. En España, las redes sociales son el segundo medio de referencia entre los jóvenes menores de 35 años, con un 62\%, solo tres puntos por debajo de la televisión (UNAV, 2014: 6).

Estas cifras responden a una dinámica que lleva años creciendo: la línea entre productor y consumidor de información se vuelve cada vez más borrosa, apostando por la fusión de ambos en la figura del prosumidor. Mucho se ha escrito sobre las oportunidades que ofrece la comunicación digital, pero los estudios empíricos existentes arrojan resultados poco optimistas. Las empresas mediáticas siguen considerando los contenidos generados por el usuario (UGC) como un modo de reducir costes; la mayor parte de los gastos en este aspecto proviene de un control editorial, no de recompensas a los contribuidores (Hermida y Thurman, 2007: 21). La integración de blogs y comentarios es muy limitada y siempre controlada, de forma que "los usuarios que 
contribuyen en los medios (por ejemplo, creando contenido) no son necesariamente quienes controlan el enfoque" (Jönsson y Örnebring, 2011: 140).

La recepción es un proceso activo: el lector construye un significado, a menudo distinto del pretendido por el emisor. El lector no asimila el mensaje tal como le es presentado, sino que primero lo interpreta y le asigna una serie de significados; "es ese conjunto de significados descodificados los que tienen un efecto" (Hall, 2004: 219). Los códigos de emisor y receptor no son iguales, sino que hay diferentes "grados de entendimiento y malentendido en el intercambio comunicativo [que] dependen ambos del grado de simetría y asimetría en la posición del producto y la del receptor" (Hall, 2004: 220). Así, la lectura hegemónica no será la única que descodifiquen los lectores: podemos encontrar interpretaciones que aceptan el grueso del mensaje pero añadiendo excepciones locales (lectura negociada) o que reubican la lectura preferente en un marco de interpretación alternativo (código oposicional) (Hall, 2004: 233-236).

Este proceso se desarrolla de forma individual, a veces incluso inconscientemente. Sin embargo, Internet y las redes sociales hacen explícita y refuerzan esta tendencia de reapropiación de los modelos ofrecidos por los media (mediatización). El lector no tiene que recontextualizar mentalmente la noticia que dan los medios, sino que la propia comunidad en Twitter o a través de un grupo de Whatsapp le proporciona otro marco de interpretación. El papel que juegan estos grupos es crucial:

Para entender la mediatización es fundamental comprender cómo se produce en un entorno de recepción en el que surgen y eventualmente se consolidan corrientes y comunidades interpretativas y afectivas y también que estas afinidades pueden ir o no acompañadas de la percepción de formar una comunidad o una colectividad. De estas consideraciones se derivan preguntas relativas a cómo abordar las dinámicas de la formación de afinidades y afectividades, de vínculos y voces; cómo se articula en las llamadas corrientes y comunidades interpretativas la percepción de formar parte de un "nosotros", de alguna colectividad singularizada (Peñamarín, 2008: 72).

Sin despreciar los agentes sociales tradicionales, hoy estos procesos de mediatización también se producen a través de redes sociales y agregadores como Reddit o Menéame, cuyos integrantes no tienen por qué conocerse personalmente sino a través de sus avatares online. Estas instancias funcionan como los líderes de opinión, solo que ahora los lectores controlan y alteran estos espacios según sus intereses. El consumo informativo digital se caracteriza porque también incorpora estos espacios al margen de los medios tradicionales, 'abriendo' así el propio proceso de lectura:

Pasaríamos de esta manera del objeto al proceso [...] Al hablar de hipermediación no nos referimos tanto a un producto o un medio sino a procesos de intercambio, producción y consumo simbólico que se desarrollan en un entorno caracterizado por una gran cantidad de sujetos, medios y lenguajes interconectados tecnológicamente de manera reticular entre sí (Scolari: 2008: 113)

Aunque el término hipermediaciones es utilizado por el autor para englobar prácticas comunicativas que van más allá del periodismo, su vigencia en el entorno informativo actual obliga su incorporación al presente trabajo. De hecho, Scolari no hace 
sino reformular una de las características básicas del hipertexto: el texto disperso. Esta estructura abierta, semejante al rizoma, incluye todo tipo de contenidos, incluidos los trabajos de otros usuarios, acabando con la llamada "voz tiránica", que muchos adalides de internet han asociado a la literatura impresa y lineal, para centrarse en un lector más activo (Landow, 2009: 89).

En este aspecto, parece lógico considerar los contenidos generados por el usuario como una vía de apertura a la ciudadanía. Sin embargo, las iniciativas puestas en práctica hasta ahora por los medios de comunicación siguen una vía menos optimista:

El término UGC representa tanto un empoderamiento de los ciudadanos como una 'ilusión interactiva': la paradoja proviene de que es difícil conseguir el empoderamiento dentro de la lógica institucional y organizacional de los medios populares (el trabajo 'empoderante' del contenido generado por el usuario tiene lugar en otra parte). Y con esta premisa como base, el rol del usuario-como-consumidor domina sobre el débil rol del usuario-como-ciudadano (Jönson y Örnebring, 2011: 141).

Esta tensión entre las posibilidades casi utópicas del ciberespacio y los intereses empresariales de los grandes medios de comunicación lleva a la proliferación de nuevos espacios informativos al margen, como hemos visto anteriormente. A diferencia de la industria periodística, controlada por las compañías y con una jerarquía muy definida, los UGC se estructuran en redes de doble sentido, donde todos actúan como prosumidores. Se trata de la autocomunicación de masas analizada por Castells:

Es autocomunicación porque potencialmente puede llegar a una audiencia global [...] Al mismo tiempo, es autocomunicación porque uno mismo genera el mensaje, define los posibles receptores y [...] las redes de comunicación electrónica que quiere recuperar. Las tres formas de comunicación (interpersonal, comunicación de masas y autocomunicación de masas) coexisten, interactúan y, más que sustituirse, se complementan entre sí (Castells, 2009: 88).

La estructura en red permite la reapropiación de contenido por parte de los nodos bien conectados. Así, un lector consume una información determinada, la reelabora de acuerdo con los criterios y necesidades de la comunidad y la comparte con el resto de integrantes de la comunidad. Esta dinámica de reapropiación forma un circuito de expresión, "con cada participante trabajando para mantener la actividad de los demás" (Jenkins, 2008: 101). Los nodos más importantes son aquellos por los que pasa más información. Los usuarios no se limitan a una sola red, como hemos visto, sino que están conectados a otras comunidades; la red se extiende más allá del grupo de amigos.

Pero no todos los usuarios discuten en el foro o elaboran complejas entradas en su blog. De la misma forma que Jenkins subrayaba que la profundidad es solo una opción, Burbules y Callister reconocen que un usuario no siempre adopta un papel tan activo: "probablemente sea imposible (y hasta indeseable) ser siempre lectores críticos que estudian todo tipo de material en forma exhaustiva" (Burbules y Callister, 2001: 121). Por esta razón, considero más adecuado hablar de la autocomunicación de masas como un fenómeno grupal en vez de referirme al prosumidor como persona que encarna ambas posiciones. 
En líneas generales, la comunicación dentro de una comunidad es horizontal frente a la jerarquía de la industria periodística. Los individuos prosumidores funcionan como emisores y destinatarios: reelaboran la información recibida, la interpretan de acuerdo con su conocimiento del mundo y la transmiten al resto de miembros de la comunidad (Castells, 2009: 182). Pero esta comunicación no sigue las normas del discurso periodístico sino que se desarrolla en un ámbito comunicativo distinto, más cercano a las lógicas de la cultura fan en la que se enmarca el análisis de Jenkins.

Esta comunicación 'informal' se basa en contenidos menos elaborados y más cercanos a la anécdota, generalmente con un tono paródico o de humor. Memes, montajes fotográficos, incluso cadenas o trending topics en Twitter sirven para comprobar que los usuarios ya se informan en largas noticias o informativos completos, sino que la carga informativa ha cambiado:

Mucha información de la que aparece en los textos sobre estos episodios permanece usualmente implícita debido a que el hablante presupone que el oyente la conoce. También se presupone que durante la comprensión el lector o el oyente activa, aplica o quizás adapta o cambia esta información del argumento. El papel de los argumentos, o formas de conocimiento parecidas, y la organización de las creencias resulta crucial en la explicación de cómo las personas entienden la información por omisión, cómo responden preguntas o proporcionan resúmenes de los textos. Estos argumentos explican cómo los lectores pueden construir una representación significativa incluso cuando el propio texto es sólo fragmentario (Van Dijk, 1990: 149).

Así, los elementos presentes en el meme o el montaje fotográfico forman una nueva red de interpretantes que cambia por completo el sentido del texto al introducir un nuevo índice: generalmente una frase sobreimpresa realizada con una tipografía muy concreta, fácilmente identificable con estos textos visuales. Este tipo de comunicación funciona porque apela a los conocimientos presentes en la enciclopedia del lector: este elige la interpretación más adecuada para el marco en que encuentra (Abril, 2013: 101). El meme cambia el marco y, por tanto, el lugar de enunciación que permite interpretar la imagen. Nos encontramos ante unas prácticas discursivas diferentes, que plantean un nuevo modo de entender la comunicación y, por tanto, la sociedad:

El mundo representado visualmente en las pantallas de los 'new media' es un mundo construido de forma distinta al representado en las densas páginas impresas de los periódicos de treinta o cuarenta años atrás. Los recursos que ofrece para entender y crear sentido difieren de los del mundo representado en el lenguaje y también los ciudadanos que produce (Kress y van Leeuwen, 2006: 31).

Los memes y demás ejemplos de comunicación informal surgen como respuesta a un cambio en las necesidades comunicativas de los individuos; parten de la posibilidad tecnológica en una era marcada por la imagen, consolidando un cambio en la sociedad. Como sostienen estos mismos autores, tal transformación necesita un proceso de alfabetización diferente para comprender el nuevo orden semiótico (Kress y van Leeuwen, 2006: 34), basado en procesos informales y apoyados en el humor. Ahora más que nunca, resulta necesario ampliar los enfoques para abarcar otras prácticas discursivas. 
La riqueza de esta producción choca contra el espacio que se sigue dando a los discursos ciudadanos en los medios de comunicación. Los estudios empíricos (Daubs, 2011; Hermida y Turman, 2007; Jönsson y Örnebring, 2011) coinciden en señalar la escasa relevancia de los contenidos incluidos: comentarios, encuestas, entrevistas abiertas a preguntas de los lectores... Las redes sociales y demás espacios al dan una libertad mucho mayor al usuario; las restricciones ideológicas y políticas continúan pero de un modo más cultural que empresarial. Estos espacios "descentralizan el flujo de información" y se han erigido en espacios de libertad, hasta el punto de que su estética "simboliza la democratización de la producción mediática y la rebelión contra los medios de masas centralizados" (Daubs, 2011: 27). Sin embargo, "los usuarios/productores deben resistir la tentación de asumir que son independientes de una cultura mediática centralizada simplemente porque producen media desde fuera de las estructuras mediáticas tradicionales" (Deubs, 2011: 239).

La respuesta de los medios no ha pasado por aumentar la producción ciudadana entre sus contenidos. En la última década, desde el auge del periodismo ciudadano, no ha aumentado la calidad de los espacios de participación, sino que la interactividad sigue relegada al papel de anécdota (Jönsson y Örnebring, 2011: 133). De hecho, los medios que incorporan piezas elaboradas por la audiencia, como la CNN, siguen imponiendo su criterio sobre las colaboraciones, reforzando la relación hegemónica con la ciudadanía (Daubs, 2011: 188).

En vez de esta incorporación de los UGC, se observa una tendencia cada vez más creciente de adoptar la estética informal de los contenidos de aficionados: animaciones planas, menús similares a los de redes sociales y, en general, un abandono de la calidad técnica hacia una improvisación muy estudiada en encuadres, planos... Esta transformación no busca simplemente 'parecer moderno' sino que responde a

los esfuerzos de la cultura dominante en la sociedad por asimilar -en vez de dominar- lo emergente; la agresividad de esta incorporación está directamente relacionada con el nivel percibido de diferencia con (y posible amenaza a) la cultura dominante. La asimilación de la cultura emergente, empero, es raramente percibida como amenaza por los miembros de esa cultura [...] Así, la cultura emergente se somete voluntaria y, quizás, inconscientemente a la cultura dominante (Deubs, 2011: 187).

El desarrollo de la tecnología y las necesidades informativas específicas de los usuarios lleva a estos a cambiar sus patrones de lectura, dejando de lado los medios de masas para participar cada vez más en redes sociales y otros espacios de comunicación informal. Este es un proceso de doble sentido: los sujetos crean más contenidos y se informan más en las redes, quizás aumentando también la calidad de estos contenidos, mientras que los medios de comunicación se esfuerzan por participar y ganar legitimidad mediante la imitación de algunas características formales de esta comunicación informal, como la estética, pero sin incorporar al medio los trabajos de estos prosumidores (Daubs, 2011; Hermida y Turman, 2007; Jönsson y Örnebring, 2011).

Esta separación genera tensiones en la lectura. La audiencia encuentra divergencias frecuentes entre los discursos de los medios y los usuarios. Estas diferencias se debaten en grupos sociales, a través de redes o grupos de mensajería instantánea como Whatsapp, donde se producen lecturas contrahegemónicas y procesos de re- 
mediación (Bolter y Grusin, 2011: 46). En estos grupos se 'reescribe' la información, aportando fuentes y documentos de muy diversa índole, creando así un hipertexto coral que forma parte del proceso informativo actual.

El periodismo deportivo constituye el objeto de estudio más adecuado porque sus características formales lo han hecho siempre la sección informativa más pegada al lenguaje cotidiano de la sociedad (De Ramón, 2011). Los programas deportivos son, además, los más conocidos por la población y con mayor audiencia, así que esta puede debatir con mayor libertad la actualidad futbolística y deportiva en general. Por si fuera poco, las ligas de fantasía actúan como aglutinadores de estas comunidades fomentando aún más el debate y la lectura crítica, además de favorecer la proliferación de páginas de aficionados que satisfagan las particulares necesidades informativas de los sujetos (Serazio, 2008:39).

En este contexto, la información deportiva parece el mejor objeto de estudio para analizar la tensión entre los discursos periodísticos y los contenidos generados por los usuarios (UGC). Para ello, me baso en el análisis del programa deportivo de mayor audiencia e impacto social en España: Deportes Cuatro, también conocido como "Los Manolos". Además del análisis del contenido, complemento la investigación con una etnografía de un grupo de Whatsapp creado para organizar una partida de Comunio, la liga de fantasía más popular en España. Esta comunidad es el objeto de estudio perfecto para evaluar las lecturas críticas y remediaciones que pueden desarrollar los ciudadanos en los espacios al margen de los medios de comunicación, tal como puede ser un servicio de mensajería instantánea. De forma complementaria, también he realizado entrevistas personales enfocadas a aclarar algunos aspectos que no quedan bien resueltos con un simple análisis del discurso.

\section{Análisis}

Aunque sería interesante, un análisis en profundidad de todo el programa de Deportes Cuatro excede con mucho un trabajo de estas características. En su lugar, voy a analizar dos secuencias pertenecientes al programa emitido el 27 de enero de 2014 a las $15: 00^{2}$. La primera de ellas, situada entre 11:45 y 14:16, es una pieza sobre la actuación del Barça y un homenaje a Xavi Hernández, mientras que la otra, entre 24:40 y 26:15, muestra un montaje sobre Cristiano Ronaldo y su obsesión por lograr la chilena perfecta. Para analizar mejor los cambios formales que plantea este programa, aportaré también ejemplos de contenidos realizados por la audiencia y las similitudes o diferencias con el programa de televisión.

\subsection{Escena 1: La exuberancia del líder}

La primera secuencia escogida presenta una crónica del partido entre el Barcelona y el Málaga adoptando una perspectiva muy particular. Se explota un tono épico para narrar el juego del Barça y se relega al Málaga a la posición de contrincante; su existencia es necesaria solo para lucimiento de los héroes barcelonistas. A continuación

Dicho programa puede consultarse en la siguiente página: <http://www.cuatro.com/deportes/programas-completos/Lunes_2_1739355144.html> [Recuperado: 20 de agosto de 2014] 
de este reportaje, se emiten unas imágenes laudatorias sobre Xavi Hernández, comentadas por los presentadores desde plató. He agrupado estas dos piezas en la misma secuencia porque sirven para analizar cómo los medios de comunicación conforman la identidad de una comunidad, a través del uso de emociones y otros recursos.

El tratamiento de la realidad que ofrecen los medios nunca es un modelo que se implante en los lectores sin modificación; "el consumo de los medios de comunicación masiva [...] produce formas de respuesta y reacción que suponen una agencia" (Appadurai, 2001: 10). De hecho, el sentido que construyen los espectadores sobre el contenido emitido no acaba en sí mismo, sino que genera comunidades de diferente tipo:

Parte de lo que los medios de comunicación de masas hacen posible, precisamente a raíz de producir condiciones colectivas de lectura, crítica y placer, es lo que en otra oportunidad denominé comunidad de sentimiento (Appadurai, 1990), que consiste en un grupo que empieza a sentir e imaginar cosas en forma conjunta, como grupo. [...] Experiencias colectivas de los medios de comunicación de masas, sobre todo el cine y el video, pueden producir hermandades y cultos basados en la adoración y el carisma (Appadurai, 2001: 11)

Las agrupaciones de hinchas de un equipo concreto reúnen estas características; los sujetos se unen en condiciones de lectura particulares, centrándose en la información de su equipo y primando (en la mayoría de casos) aquellas noticias que elogian a su club. Podríamos afirmar que estas comunidades son afuncionales y horizontales, además de superar en ocasiones lo local (propio de clubes pequeños, muy identitarios en lo regional) para formar grupos translocales, en torno a un símbolo mundial como pueden suponer Barça o Real Madrid. Por lo tanto, nos encontraríamos ante un tipo de comunidad lúdica, con vinculaciones supuestamente débiles y transitorias, aunque la vivencia del fútbol en España parece desmontar este supuesto.

Los periodistas deportivos siempre han aprovechado estas comunidades para presentar la información. Por una parte, la información sobre los dos grandes equipos españoles (Barça y Real Madrid) ocupa más tiempo en los informativos por un simple proceso de prioridad informativa: al haber más seguidores de estos dos clubes, hay un porcentaje mayor de la población a quien le interesa esta información. Pero este procedimiento estrictamente periodístico tiene otra cara: al centrarse en Barça y Madrid se construye la realidad en torno a ellos, siendo el resto de equipos meras comparsas de la bipolaridad futbolística.

Este efecto se refleja claramente en la primera escena analizada de Los Manolos: una crónica laudatoria del Barça. El partido no se construye sobre la base de un encuentro entre dos equipos, sino sobre la soberbia actuación del Barcelona. El lenguaje utilizado es claramente épico, con recurrentes figuras retóricas como paralelismos ("Bienvenidos a...", "lo son porque...", "es la historia de...") y concatenaciones de adjetivos muy marcadas por el narrador ("llegan como motos, desbocados, hambrientos", "es el ataque total, irrefrenable"). El montaje subraya este efecto que podríamos definir como poético o publicitario: planos rápidos, de menos de 3 segundos, muchos de ellos en movimiento o seguidos para aumentar la sensación de velocidad. Fundidos a rojo y colores vivos, además de narrar una misma acción desde varios enfoques distintos, un recurso muy cinematográfico (minuto 12:04, figura 2). En definitiva, una presentación creada para los seguidores del Barça. 

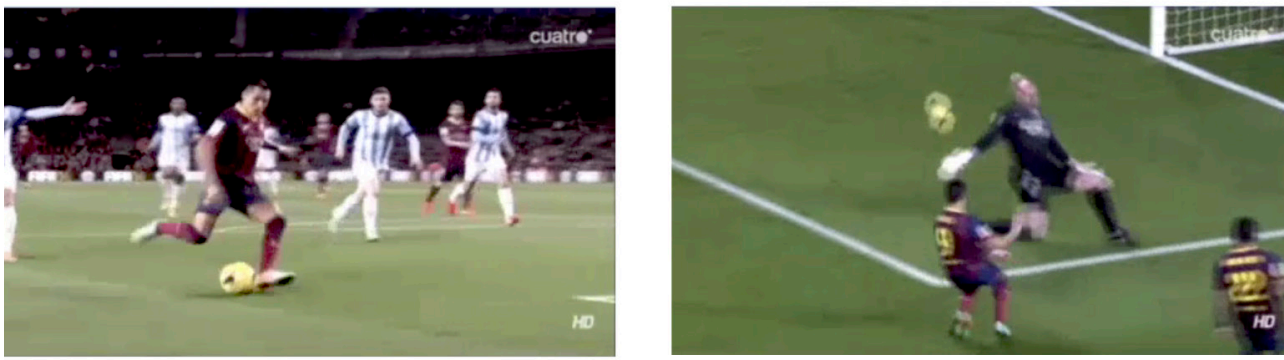

Figura 2. Misma escena presentada desde planos distintos

Aunque la información deportiva en general también se centra más en la actualidad de estos dos equipos, ningún otro informativo utiliza un lenguaje de este tipo. Por ejemplo, el Telediario (TVE) calificó el partido de "tranquilo" y solo destacó "la mano decisiva" del portero barcelonés, Víctor Valdés ${ }^{3}$. Una explicación puede apoyarse en el análisis de la cultura fan que realizó Henry Jenkins. Para este autor, los fans (en este caso, hinchas de un equipo) tienen unas necesidades comunicativas diferentes al resto de sujetos y se esfuerzan por satisfacerlas:

Los fans constituyen el segmento más activo del público mediático, que se niega a aceptar sin más lo que le dan e insiste en su derecho a la participación plena. Nada de esto es nuevo. Lo que ha cambiado es la visibilidad de la cultura de los fans. La red proporciona un nuevo y poderoso canal de distribución para la producción cultural aficionada (Jenkins, 2008: 137).

Parece adecuado señalar que Los Manolos surge para saciar a estos consumidores. De hecho, sus características formales parecen incluso englobarlo dentro de la comunicación fan, pero nada más lejos de la realidad. Como apuntaban estudios precedentes, la estética de los programas periodísticos intenta acercarse a la audiencia pero no se incorporan contenidos de los usuarios (Daubs, 2011: 193). Las entrevistas personales servirán para comprobar la percepción del público a este respecto.

Este proceso de cambio estético es de doble sentido. Mientras que los espacios informativos incluyen montajes más ágiles, con planos más cortos y acrobáticos al estilo del cine comercial o la publicidad, muchos contenidos de los fans adoptan un tono más 'periodístico'. Aunque muchos de ellos sigan siendo homenajes a ídolos como Messi o Guardiola, la calidad del producto final no se aleja demasiado de las obras profesionales. En parte, esto es debido a que los usuarios trabajan con las grabaciones de los partidos realizadas por televisiones; esto no deja de ser el principio básico de la remediación e, incluso, del propio lenguaje digital:

Un objeto de los nuevos medios no es algo fijado de una vez para siempre, sino que puede existir en distintas versiones, que potencialmente son infinitas [...] Se puede pensar en los nuevos medios en general como si constaran de dos capas diferenciadas: la «capa cultural» y la «capa informática» [...] Cabe esperar que la capa informática afecte a la capa cultural. Las maneras en que el ordenador 
modela el mundo, representa los datos y nos permite trabajar; las operaciones fundamentales que hay tras todo programa informático y las convenciones de su interfaz [...] influyen en la capa cultural de los nuevos medios, en su organización, en sus géneros emergentes y en sus contenidos (Manovich, 2005: 93).

Así, aunque la tecnología utilizada por periodistas y aficionados sea muy similar, los códigos culturales con que operan cada uno son diferentes. Un fan no realizará un programa informativo simplemente porque tenga acceso a las grabaciones; su intención comunicativa es bien diferente. Este es el salto en los contenidos generados por los usuarios actuales: no solo se destinan expresar su admiración por un personaje sino que pretenden informar. Por ejemplo, resulta fácil encontrar documentales realizados por aficionados al cine cuyo montaje no se diferencia del programa Los Manolos ${ }^{4}$ :
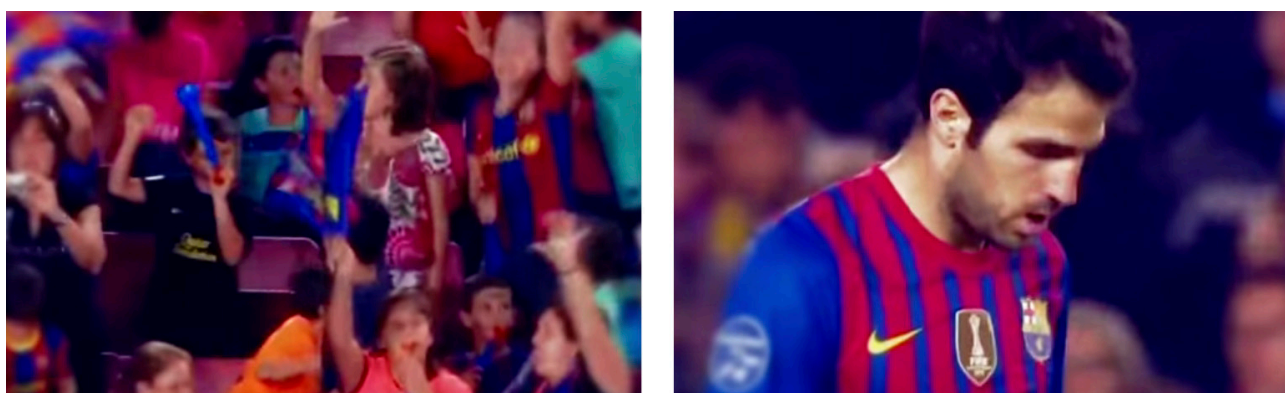

Figura 3. Planos del documental realizado por un aficionado. Fuente: Lebo Akaitio

De hecho, algunos ejemplos de esta autocomunicación de masas presentan informaciones difíciles de encontrar en los grandes medios, como análisis detallado de cada jugada o valoraciones de todos los jugadores, como muestra el vídeo siguiente ${ }^{5}$. Más adelante analizaremos estas valoraciones como un elemento central de la cultura actual.
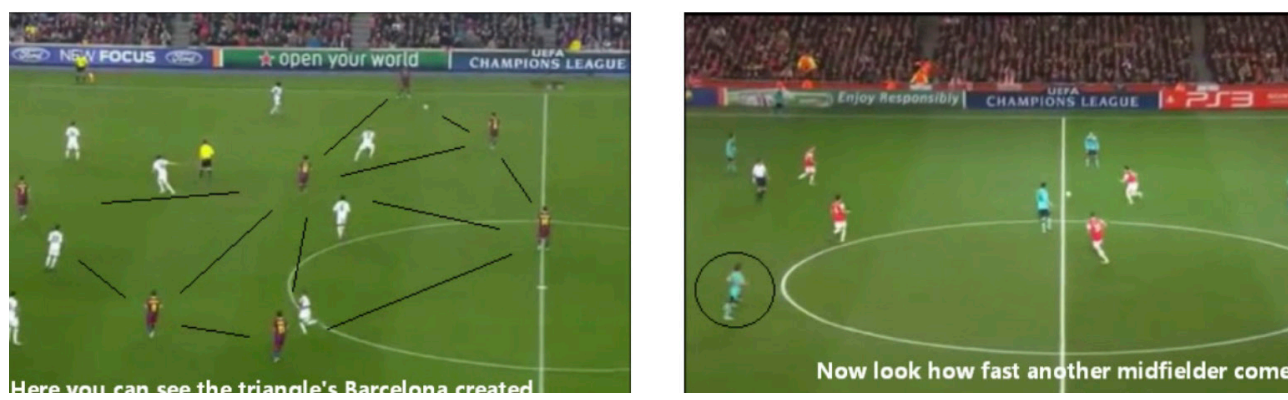

Figura 4. Análisis de jugadas realizado por un aficionado. Fuente: Barcelona Tiki Taka

$4 \quad$ Para apreciar el montaje, puede encontrarse el vídeo completo en $<\mathrm{https}$ :/www.youtube.com/watch?v=pk1DQBruwnQ> [Recuperado: 20 de abril de 2017]

5 El vídeo completo puede encontrarse en $<$ https://www.youtube.com/watch? $\mathrm{v}=1 \mathrm{GuaQ} 1 \mathrm{khn} 2 \mathrm{k}>$ [Recuperado: 20 de abril de 2017] 
Algunos de estos contenidos no siguen el formato de los espacios informativos clásicos, sino que están destinados a saciar necesidades informativas específicas. Por ejemplo, la página web Comuniazo informa de las puntuaciones de los jugadores según el baremo del juego de liga de fantasía Comunio. Este portal remedia las valoraciones de los periodistas del diario As y las presenta en los términos específicos que utilizan los usuarios de este juego. El análisis conversacional de estas comunidades permitirá comprender mejor este lenguaje específico de los participantes en Comunio.

Si los contenidos de los aficionados presentan este grado de elaboración, las características formales de Los Manolos pueden llevar a pensar que este espacio carece del rigor periodístico propio de estos programas. De hecho, parece haber ocasiones en las que parece abandonarse la pretendida objetividad y se abraza la opinión personal. Es el caso del homenaje a Xavi Hernández en el minuto 13:30, cuando los presentadores realizan los siguientes comentarios:

Manu Carreño: Hay que seguir cuidando a este futbolista.

Manolo Lama: Con todos los respetos, que nadie se enfade, para mí el mejor jugador nacional de la historia.

Manu Carreño: Para mí también. Firmo debajo: el mejor español de todos los tiempos, sin duda. Xavi Hernández, habrá un antes y un después de su marcha. Pero todavía le queda, no lo jubilemos.

Obviamente, la valoración de los presentadores es una opinión personal basada en su criterio. Sin embargo, esta afirmación no extraña tanto al espectador porque está acostumbrado a este tipo de juicios en la prensa deportiva, en primer lugar, pero además porque refleja el consenso social (De Ramón, 2011: 76). Estamos ante la misma razón por la que resulta natural alabar los partidos del Barcelona por su buen juego y la calidad de sus jugadores: es el significado creado por un gran sector de la población, es decir, una semiosfera.

La existencia de una cultura plantea la necesidad de otra para establecer una frontera entre ambas, un lugar donde traducir el sentido que producimos, nuestro lenguaje. Dado que en el interior de una semiosfera la producción de significado tiene cierta homogeneidad, necesitamos un espacio de traducción a otros lenguajes: esta es la frontera.

Así como en la matemática se llama frontera a un conjunto de puntos pertenecientes simultáneamente al espacio interior y al espacio exterior, la frontera semiótica es la suma de los traductores 'filtros' bilingües pasando a través de los cuales un texto se traduce a otro lenguaje (o lenguajes) que se hallan fuera de la semiosfera dada. El 'carácter cerrado' de la semiosfera se manifiesta en que ésta no puede estar en contacto con los textos alosemióticos o con los no-textos. Para que éstos adquieran realidad para ella, le es indispensable traducirlos a uno de los lenguajes de su espacio interno o semiotizar los hechos no-semióticos. Así pues, los puntos de la frontera de la semiosfera pueden ser equiparados a los receptores sensoriales que traducen los irritantes externos al lenguaje de nuestro sistema nervioso (Lotman, 1996: 24).

Volviendo al ejemplo del homenaje a Xavi Hernández, tales alabanzas pueden formar parte de una semiosfera ya asumida por el espectador, en cuyo caso es un jui- 
cio compartido por ambos, o bien encontrarse fuera. En este caso, el sujeto traduce el texto (halagos) a su propio lenguaje. Alguien ajeno al ámbito futbolístico puede encontrarse en esta posición, no ha naturalizado la admiración por dicho jugador y debe traducirlo a su propio lenguaje. Por ejemplo, puede recordar los títulos que ha ganado con su equipo y con la selección española, imágenes que han traspasado la cultura meramente deportiva.

Por esto, resulta fundamental examinar las emociones que operan en esta escena. Apenas hay encuentros neutrales con otros objetos, que no sean positivos o negativos en términos emocionales. Por eso resulta indispensable repasar las emociones que suscita el texto, así como los lugares comunes en los que opera para lograr este fin. Retomando los objetivos de la acción política desarrollados por Jasper, podríamos encontrar apelaciones a un sentimiento de orgullo o reconocimiento (Jasper, 2012: 51). La épica en la narración de las jugadas del Barça subraya ese orgullo presente en los fans, basándose a su vez en el sentimiento de pertenencia a esa comunidad.

Podría incluso afirmarse que los partidos semanales y los posteriores comentarios en los medios de comunicación como Los Manolos conforman un tipo de rituales de interacción (trabajando sobre términos tomados de Durkheim y Goffman) que 'activan' el sentimiento de pertenencia (Jasper, 2012: 55). De esta manera, la pertenencia como emoción de fondo se concreta en un momento específico y provoca acciones concretas, como informarse sobre el partido o defender al equipo, que subrayan el sentimiento de comunidad.

\subsection{Escena 2: En busca de la chilena perdida}

La segunda secuencia analizada corresponde a un montaje elaborado por los periodistas sobre la obsesión de Cristiano Ronaldo por lograr un gol de chilena. Para ello, no utilizan una pieza corriente locutada sobre imágenes de partidos. En su lugar, presentan una historia ficticia del jugador visionando una y otra vez goles de chilena.

El primer elemento que llama la atención es la caracterización de Cristiano Ronaldo: claramente no se trata del personaje real sino de un montaje (figura 3). Resulta importante porque los periodistas ni reconocen ni disimulan la farsa; asumen que el espectador es suficientemente competente y confían en su enciclopedia personal para construir el significado de la pieza.
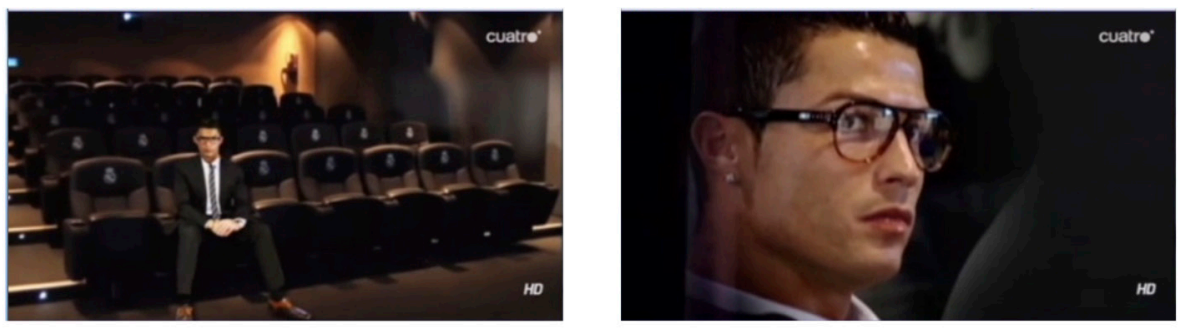

Figura 3. Planos del documental realizado por un aficionado. Fuente: Lebo Akaitio 
Podemos reconocer en este montaje una clara influencia de la cultura visual propia de los memes y otros contenidos generados por los usuarios en internet. Por una parte, podríamos considerarlo un caso de dialogismo, puesto que operan sobre este texto visual varias agencias:

La concepción por la palabra del objeto de la misma es un acto complejo: de una parte, todo objeto 'condicionado' y 'contestado' es iluminado; de otra, es oscurecido por la opinión social plurilingüe, por la palabra ajena acerca de él; la palabra entra en el complicado juego del claroscuro (Bajtin, 1989: 94).

Pero por otra parte, también podríamos interpretarlo como hibridación, puesto que se trata de un recurso visual perteneciente a otra cultura (montajes caseros, aficionados) que ya no necesita ser traducida puesto que ha sido incorporada a la propia semiosfera de la industria periodística. Así, resulta cada vez más frecuente encontrar piezas periodísticas grabadas en baja resolución, con planos que se mueven y otros rasgos considerados hasta ahora "poco profesionales" (Daubs, 2011: 177).

Hay más elementos dialógicos: la música y el 'título' de la pieza, vinculados a En busca del arca perdida; el rótulo de Valdebebas que aparece al principio, típico de películas de espías; el lenguaje empleado por el narrador, falsamente grandilocuente; el apodo de 'CR Chilena 7'... Toda esta red de apropiaciones con un claro objetivo, burlarse de la obsesión de Cristiano Ronaldo por marcar un gol de chilena, puede llevar a considerar esta noticia como una parodia:

Toda parodia, todo transformismo, toda palabra utilizada con reserva, con ironía, puesta entre comillas entonativas; en general, toda palabra indirecta, es un híbrido intencionado; aunque híbrido monolingüe, de orden estilístico. En realidad, en la palabra paródica convergen, y en cierta manera se cruzan, dos estilos, dos lenguajes (interlingüísticos): el lenguaje parodiado -por ejemplo, el de un poema heroico- y el que parodia -el lenguaje prosaico vulgar, el familiar oral, el de los géneros realistas, el lenguaje literario "normal", "sano", tal y como se lo imagina el autor de la parodia. Ese segundo lenguaje que parodia, en cuyo trasfondo se construye y se percibe la parodia, no entra él mismo en la parodia -si es una parodia en sentido estricto-, pero está presente en ella de manera invisible (Bajtin, 1989: 441)

La parodia todavía es algo extraño en programas de información como Los Manolos. Este tipo de contenidos son frecuentes en espacios híbridos, llamados 'infoentretenimiento', como El Intermedio, en La Sexta. Sin embargo, estos programas están desligados por completo de los servicios informativos de la cadena, y son tomados como tal. El ejemplo analizado puede explicarse profundizando en la semiosfera de la que forma parte la información deportiva; este género ha utilizado el humor y las bromas desde hace décadas. Como apunté en el apartado anterior, el discurso de los medios de comunicación se enmarca en una semiosfera concreta, utilizando su lenguaje; por tal razón este tipo de contenidos no 'chocan' a un espectador perteneciente a esta comunidad.

No obstante, sí es cierto que la inclusión de este tipo de lenguaje visual (montajes no profesionales) remite al meme y, por tanto, construye un tipo de mirada distinto. Un texto visual comprende tres dimensiones: visualidad, imagen y mirada. No se trata de establecer "ámbitos cerrados sino más bien delimitados de forma imprecisa", 
una relación donde "cada dimensión hace posible la interrelación y efectuación de las otras" (Abril, 2013: 49).

La inclusión del montaje de Cristiano Ronaldo opera como un cambio de mirada porque genera una nueva posición enunciativa. Por una parte, se produce un distanciamiento respecto a la pieza periodística al comprobar su intención satírica. Pero por otra parte se produce cierta complicidad entre autor y lector al sentirse copartícipes de una broma. De hecho, la propia introducción que hacen los dos presentadores a la pieza ilustra esta posición:

Manolo Lama: Sigue siendo la asignatura que sigue teniendo pendiente. Por eso, ¿sabes qué película se ha ido a ver?

Manu Carreño: Sí, me gusta esa película.

Manolo Lama: En busca de la chilena perdida.

Esta sintonía entre periodistas y espectadores secunda la idea de Los Manolos como un ejemplo de programa perteneciente a la cultura fan. Antes ya he apuntado algunas de sus características, como unas necesidades informativas específicas y la organización en comunidades translocales, informales y horizontales Las razones de este modelo son diversas:

La nueva cultura del conocimiento surge a medida que nuestros vínculos con formas previas de comunidad social se van rompiendo, nuestro arraigo en la geografía física disminuye, nuestros lazos con la familia extensa e incluso nuclear se desintegran y nuestras lealtades a los Estados-nación se redefinen. No obstante, surgen nuevas formas de comunidad: estas nuevas comunidades se definen mediante afiliaciones voluntarias, temporales y tácticas, reafirmadas en virtud de empresas intelectuales e inversiones emocionales comunes (Jenkins, 2008: 37).

Inmerso en esta nueva cultura participativa, Los Manolos ha construido un enunciatario muy diferente al de otros informativos deportivos. No se trata solo de la inclusión del montaje de Cristiano Ronaldo, sino el tipo de edición en todas sus piezas (mucho más ágil, casi publicitario), los diálogos entre los presentadores... Incluso la falta de interés por mostrar los resultados de los partidos (ni siquiera se han mostrado en una pieza propia, sino en imágenes locutadas desde plató) puede interpretarse como una presunción de un espectador bien informado, que acude a Los Manolos para ver algo más, una visión diferente al del resto de cadenas, la única que puede saciar sus necesidades informativas particulares.

Este análisis permite comprobar la adecuación del programa a la tendencia del periodismo actual, consistente en incorporar cada vez más recursos estilísticos propios de la comunicación informal entre aficionados, como son parodias, dialogismos, conversaciones naturales... El periodismo deportivo siempre ha sido un caso peculiar de equilibrio entre esta naturalidad, "el lenguaje de la calle", y la objetividad periodística. Los Manolos siguen caminando en esta delgada frontera para reforzar la tradicional función de los medios de comunicación de generar comunidad, algo más difícil en una audiencia diseminada por las redes sociales. 


\section{Recepción del discurso periodístico}

Una vez estudiados los cambios formales en el discurso periodístico y su comparación con los contenidos generados por los usuarios actuales, paso a presentar el estudio conversacional sobre la recepción de estos (y otros) medios de comunicación. Este análisis puede dividirse en dos partes: el análisis de la recepción del discurso periodístico a través de los discursos producidos por una comunidad de usuarios en Whatsapp y, posteriormente, las entrevistas personales planteadas a algunos de los sujetos. Este método permite estudiar por una parte "las dinámicas de la formación de afinidades y afectividades, de vínculos y voces" en una comunidad (Peñamarín, 2008: 72) y todos los demás mecanismos sociales que no afloran en una práctica social de estas características.

La comunidad que voy a analizar está compuesta por diez personas: nueve hombres y una mujer, pareja de otro integrante del grupo. No todos se conocen personalmente, aunque todos viven en Zaragoza y alrededores. El grupo actual es resultado de la evolución de una comunidad durante varios años; algunos jugadores que servían de enlace han salido del grupo, dejando a personas que no se conocen más allá del grupo de Whatsapp. Las características técnicas del servicio de mensajería definen algunas de los rasgos de la comunidad: grupo privado, comunicación multimedia (se pueden insertar emoticonos, imágenes, vídeos...) e hipertextual (enlaces a páginas web).

El texto de análisis es el resultado de las conversaciones entre los diez integrantes del grupo durante toda una jornada. Destaca el modo en que se integra el consumo informativo en la comunidad. Los integrantes son, por una parte, comentaristas deportivos al ir narrando en directo los acontecimientos importantes de los partidos. De esta forma, el grupo se convierte en un ejemplo de la autocomunicación de masas: no solo presenta información de interés específico para el grupo, sino que además remedia el discurso periodístico a las necesidades informativas propias de la comunidad.

22:06 - Jose Antonio: Ha metido Griezmann?

22:11 - José: Si, ha marcado griezman, pero yo se lo daba a Damián

22:13 - Jose Antonio: Para no darle puntos a Rubén no?

22:13 - Jose Antonio: Jjajaja

22:13 - José: Exacto

22:13 - José: Gol de griezman ahora

22:13 - Álex: Pues ale el segundo

22:14 - José: Villarato

22:15 - Jose Antonio: joer

22:15 - Jose Antonio: Si mete Carlos Martinez avisar

22:15 - Jose Antonio: Jajajaj

Este ejemplo muestra cómo se aporta la información: los miembros que están viendo el partido en directo comentan lo que ocurre, mientras que los demás preguntan por aspectos específicos del encuentro. Al jugar a Comunio, sus intereses se centran en aquellos jugadores que tienen alineados; por eso preguntan por ellos y hacen bromas sobre los autores de los goles. Esta información personalizada no se puede comparar con la presentación de los grandes medios, muy alejados de esta realidad social. 
Por otra parte, la comunidad también critica las informaciones y calificaciones cuando creen que no son correctas:

14:25 - José: Ya han salido los puntos del partido de la mañana?

14:25 - Ruben: Liga BBVA » Almería - Getafe | Comuniazo - http://www.comuniazo.com/liga-bbva/585/almeria-getafe

14:26 - Ruben: $\mathrm{Si}$

14:26 - José: Esteban?

14:32 - Álex: 10

14:39 - Jose Antonio: Esta jornada vaya puntuaciones están dando

14:39 - Jose Antonio: Ha habido un montón de críticas por twitter

14:43 - Luis: Y pedro León 6 solo...

14:43 - Luis: Se merecía 10

14:43 - Luis: Ha sido el mejor del partido

14:49 - Ruben: No creo q se den muchos 10 si tu equipo no marca y pierde

14:49 - Jose Antonio: Keylor Navas ayer debió de hacer partidazo y paro un penalti

14:50 - Luis: No Rakitic al palo

14:50 - Jose Antonio: Y le han dado un 10

En este ejemplo se perciben ciertos detalles de la lectura crítica que apuntaban Burbules y Callister, entre otros. Al igual que en las conversaciones mantenidas en cualquier otro espacio, los miembros del grupo se muestran críticos también con los demás miembros, pero siempre aportando argumentos. El análisis de la conversación arroja más ejemplos de esta situación:

22:05 - José: Si es gol de Saúl el de ayer, este es de Damián 22:06 - Álex: No xk el tiro de griezman iba direccion portería

22:06 - Álex: El de costa no iba ni a sake de puerta jejejejejejeje

22:06 - Luis: Pero deberían darselo a Damian porque le rebota

22:06 - Luis: Una vez que la toca

22:07 - Luis: Igual que cuando una falta da en el palo

22:07 - Luis: Rebota en el portero y se mete

Sin embargo, también se dan situaciones en las que se cuestiona el propio consumo de información de alguno de los miembros del grupo, tal como muestra el siguiente caso:

18:22 - Jose Antonio: Lo estás viendo o lo escuchas?

18:22 - Jose Antonio: Una pregunta Luis

18:24 - Luis: Siempre lo suelo tener puesto en Internet

18:24 - Luis: Dime

18:25 - Jose Antonio: Te tragas los 9 o 10 partidos?

18:26 - Luis: Muchos de ojeada

18:27 - Luis: Pocos veo con interés 100\%

18:28 - Luis: Es si estoy en casa cuando tengo puesto el ordenador que echan todos en la misma página 
En este caso, podemos comprobar la carga perlocutiva de la pregunta (Calsamiglia y Tucson, 1999: 197) para cuestionar la información que está recibiendo uno de los sujetos. Como podemos ver, la pregunta del primer hablante (" $¿$ Te tragas los nueve o diez partidos?") funciona en su nivel locutivo como una simple pregunta; es así como primero responde su interlocutor. Sin embargo, este pronto comprende que había algo más detrás de ese enunciado: su acto ilocutivo tenía cierto tono de crítica. Esto se traduce en el nivel perlocutivo en cierta vergüenza y este individuo siente que debe justificarse, de ahí su última respuesta.

Para terminar con el análisis de la comunicación dentro del grupo, me gustaría utilizar un último concepto que creo que servirá para comprender parte de la cultura de masas: el mito de Barthes. El autor utiliza esta idea para hablar de un habla (imagen, palabra, vídeo) que ha trascendido su simbolismo primero:

El mito es un sistema particular por cuanto se edifica a partir de una cadena semiológica que existe previamente: es un sistema semiológico segundo. Lo que constituye el signo (es decir el total asociativo de un concepto y de una imagen) en el primer sistema, se vuelve simple significante en el segundo. Recordemos aquí que las materias del habla mítica (lengua propiamente dicha, fotografía, pintura, cartel, rito, objeto, etc.), por diferentes que sean en un principio y desde el momento en que son captadas por el mito, se reducen a una pura función significante: el mito encuentra la misma materia prima; su unidad consiste en que son reducidas al simple estatuto de lenguaje (Barthes, 1986: 111).

Barthes recoge en su obra diversos ejemplos: el bistec con patatas, la vuelta a Francia... Todos ejemplos son signos que han trascendido su significado primero (comida suculenta, deporte nacional) y han adquirido la noción de mito: representación de Francia, lucha épica del hombre contra sus limitaciones.

Retomo este concepto porque creo que es el más ajustado para un fenómeno creciente en nuestra sociedad: la extrapolación de lenguajes específicos (concretamente, la puntuación numérica) para describir todo tipo de experiencias. Esta "revolución lingüística" se extiende a los vinos, la música y la literatura (Baricco, 2011: 48). El sistema de puntuaciones de Comunio, el juego sobre el que se organiza la comunidad de Whatsapp que estoy analizando, evalúa a los jugadores con valores positivos o negativos, normalmente comprendidos entre -4 y 14 (puntuaciones más extremas son hazañas harto excepcionales). Pues bien, la tendencia a comentar comportamientos o actuaciones ajenas al ámbito futbolístico con esta misma escala. He aquí dos ejemplos del texto analizado:

11:27 - Paco: Como va nadal???

11:28 - Jose Antonio: Perdiendo dos sets a 0

11:28 - Jose Antonio: Y 5-2 en el tercero

11:29 - Paco: Ganando el 3???

11:29 - Jose Antonio: Si

11:29 - Jose Antonio: Infiltrado

11:30 - Luis: Le habrán dado un relajante o algo

12:29 - Ruben: Eso es un -2

18:06 - Santiago: Hay manifestacion de los despedidos de cocacola justo enfrente del estadio 
18:06 - Luis: Estás cerca o que Santi?

18:06 - Luis: Jaja

18:07 - Santiago: Mas tocineras que nunca $\mathrm{xD}$

18:07 - Luis: No la lies Santi jaja

18:07 - Jose Antonio: Recuerda que cada noche en comisaría es -2

El mito de Barthes sirve para analizar esta expresión descontextualizada. Puede parecer un uso un poco forzado de este concepto, pero el propio autor reconoce su amplitud:

Si el mito es un habla, todo lo que justifique un discurso puede ser mito. El mito no se define por el objeto de su mensaje sino por la forma en que se lo profiere: sus límites son formales, no sustanciales. ¿Entonces, todo puede ser un mito? Sí, yo creo que sí, porque el universo es infinitamente sugestivo [...] Un árbol es un árbol. No cabe duda. Pero un árbol narrado por Minou Drouet deja de ser estrictamente un árbol, es un árbol decorado, adaptado a un determinado consumo, investido de complacencias literarias, de rebuscamientos, de imágenes, en suma, de un uso social que se agrega a la pura materia (Barthes, 1986: 108).

Aplicar las puntuaciones a elementos ajenos al ámbito del juego constituye un uso social de este acto de habla, limitado por aspectos formales. Ya hemos visto que muchos contenidos generados por los usuarios incorporan este sistema de evaluación en sus crónicas, de forma que se trata de un mito, una visión del mundo compartida por buena parte de la sociedad. Evaluar numéricamente las cosas según su calidad es una tendencia creciente en muchos ámbitos (vino, videojuegos, álbumes de música); puntuar a los jugadores con el baremo de Comunio es un ejemplo más de una práctica extendida entre la sociedad.

Los análisis anteriores han permitido responder a varios de los objetivos planteados en la investigación. Sin embargo, los cambios sobre el consumo informativo y la percepción de los sujetos respecto a medios periodísticos y contenidos generados por el usuario (UGC) todavía no han quedado plenamente recogidos. Las entrevistas personales responden estas cuestiones, además de cerrar algunos temas que habían quedado pendientes en ambos análisis.

Todos los sujetos, incluidos los menos activos en las comunidades, coinciden en señalar los cambios que provoca el juego en el consumo informativo. Los participantes ven muchos más partidos y leen noticias sobre equipos que antes no les interesaba:

Sujeto 1: Cuando llevas ya un tiempo jugando a Comunio te sorprendes porque ves partidos que no te interesan una mierda. Llega el fin de semana y no estás solo con tu equipo, sino que te tragas un Celta-Sevilla para ver si Gameiro te marca gol. Y cuando lo hace, coges en seguida el Whatsapp para decir algo por el grupo y meterte con el otro que ibas reñido. Te tragas partidos mierda pero porque ya no te interesa ni el partido; hay veces que estás jodido porque un delantero tuyo juega contra tu portero. Ahí no sabes con quién ir de los dos.

Resulta significativo que el testimonio anterior pertenezca a uno de los sujetos poco activos. Reconoce que ahora tiene "siempre el Marca de fondo", aunque no 
habla demasiado por el grupo de Whatsapp con sus amigos "porque siempre están discutiendo sobre chorradas". Esta opinión es compartida incluso por un sujeto muy activo a través de foros y redes sociales:

Sujeto 2: En el grupo de Whatsapp de la liga no hablo casi nunca porque lo que dicen no me aporta nada. Este juego trata de saber mucho de fútbol, gana el que más sabe. Solo me meto a Whatsapp para picar a los demás y compartir alguna foto graciosa. Si quiero enterarme de algo de verdad miro los foros o me meto a Twitter $[\ldots]$ Tampoco me fío de todo lo que leo porque hay mucha basura. Cuando llevas ya un tiempo vas viendo quién sabe realmente de esto, quién tiene buena información, y quién vende humo una jornada tras otra. Una mala fuente puede arruinarte una jornada y ya no ganas la liga.

Otros dos sujetos entrevistados coinciden en diferenciar claramente las conversaciones que mantienen con sus compañeros por Whatsapp (todos usan este servicio de mensajería) de la información que reciben por redes sociales y medios de comunicación tradicionales. Al profundizar en este asunto, las respuestas son variadas:

Sujeto 2: Sí, claro que te enteras de muchas cosas porque las ponen tus amigos por el grupo, pero muchas veces no son más que chorradas o bulos de que se ha muerto alguien famoso. Eso no es información porque no hacen más que pasarte un enlace, y muchas veces la gente no sabe ni quién es ese que se ha muerto. Facebook o Twitter tampoco te creas que es mucho mejor, pero al menos sigo a gente que sabe un poco más de las cosas. Entre lo que publican los periodistas y lo que dice alguno, te puedes hacer una idea de lo que realmente pasa en el mundo.

Sujeto 3: La cosa de Whatsapp es que depende mucho del grupo que tengas. Un año hice una liga con mis compañeros de clase y estábamos muy picados a ver quién sabía más de jugadores y de tácticas (dos entrenan a chavales). Pero estos últimos años no se habla de nada bueno, o de nada nuevo; todo es criticar lo que dicen los periodistas y ya está. Los periódicos son una bazofia, todo el mundo lo sabe. Como dice el Cholo: no consuman medios, todos mienten.

Sorprende que los sujetos no conciban la comunicación por Whatsapp como un medio de informarse, sino que esta función queda reservada para los medios tradicionales y las redes sociales. Cabe interrogarse si esto se debe a que no son plenamente conscientes de la importancia de ciertos procesos comunicativos o si bien el afán excesivo del investigador tiende a sobredimensionar ciertas prácticas sociales. En cualquier caso, la participación en Comunio ha cambiado la concepción sobre los medios de comunicación:

Sujeto 4: Yo antes leía el Marca, porque soy del Madrid, pero desde que juego leo más el As porque son los que ponen las picas. Para enterarme en directo de los puntos, me meto en Twitter y sigo a los periodistas que dicen verdades, cosas creíbles. Me he dado cuenta de que ahora ya no presto tanta atención a los periódicos, sigo a gente concreta que me va a contar cosas que me interesan. 
Este cambio, una de las características de la comunicación digital, es para los entrevistados una consecuencia de jugar a Comunio. Hasta su incorporación, estos sujetos seguían leyendo medios tradicionales sin participar mucho en las redes sociales; la participación en esta liga de fantasía conlleva una mayor implicación en la autocomunicación de masas. Ahora bien, ¿cuántos de estos usuarios crean o remedian información que luego comparten por las redes sociales?

Como apunta la selección de perfiles, solo los dos sujetos más activos participan en foros o páginas web. Aunque uno realizó en una ocasión "un vídeo sobre un partido del Atleti en la Romareda", sus aportaciones se limitan a corregir las informaciones de los periodistas o pronosticar las alineaciones de la próxima jornada. Este proceso sí que es percibido como algo importante, dentro de la modestia de la acción individual:

Sujeto 1: Lo que pasa es que no puedes aportar mucho en internet, porque siempre hay gente que sabe mucho más que tú. Entonces lo que haces es contrastar lo que dicen varios medios, enterarte de lo que hacen en los entrenamientos para mirar si han tenido lesiones frecuentes... Pero aunque parezca que no, es un trabajo importante porque entre todos los del foro acabas sacando cosas que no saben los periodistas y que acaban siendo verdad. Eso te da la vida en el Comunio.

En su testimonio, este sujeto resume muchos conceptos clave que han aparecido a lo largo de todo el trabajo: remediación, lectura crítica, debates... La autocomunicación de masas es un proceso social llevado a cabo por toda la sociedad, de forma que cada persona aporta su granito de arena. La colaboración del otro sujeto muy activo también es muy similar:

Sujeto 3: Paso mucho tiempo en Twitter y hablo bastante porque sigo las cuentas de periodistas y gente que sabe de deporte. Siempre proponen algún tema de conversación o hablan de un tema que yo conozco mejor que ellos. Por ejemplo, han hablado de los fichajes y ventas del Atleti, pero se equivocan mucho y más de una vez acabas discutiendo con ellos porque no tienen ni idea [... Una vez, en un programa de televisión se equivocaron al hablar del año en que el Atleti ganó la liga; les mandé un tuit y lo sacaron, reconociendo que se habían equivocado.

Los ejemplos de los sujetos entrevistados corroboran algunas de las promesas de las redes sociales y el periodismo ciudadano, como un mayor control por parte de las personas. Sin embargo, como reconocía otro usuario antes, los medios siguen condenados por su escasa credibilidad. El choque entre medios de comunicación y contenidos generados por el usuario parece saldarse a favor de este último, vistos los últimos testimonios, pero no siempre es el caso:

Sujeto 5: No me gusta Twitter porque nunca sabes si lo que te están contando es verdad. Tienes que andar con mucho cuidado porque siempre sale el bulo de que se ha muerto algún famoso, incluso los medios acaban publicándolo. Por eso confío más en el Marca y en los periódicos de siempre, porque aunque tengan sus defectos siguen siendo profesionales a los que les pagan por eso. Su trabajo es enterarse del fútbol, conque seguro que saben más que cualquier pringado como yo. 
Resulta interesante que, a pesar de criticar los medios de comunicación tradicionales, todos los sujetos siguen consumiéndolos en un soporte u otro; de hecho, dos de ellos compran el diario en papel, acción poco frecuente en los jóvenes. Además, solo dos de ellos, los más activos, consideran las redes sociales como fuente válida de información; esto puede deberse a su participación en la autocomunicación de masas. No obstante, ellos son los primeros escépticos en calificar estos procesos de revolución o incluso cambio:

Sujeto 2: No creo que Whatsapp sirva para informarse bien. A ver, si que comentas algún partido en directo y te enteras de los goles, o alguna vez que ha pasado algo gordo como lo del rey pues la gente iba poniendo ahí todo lo que se enteraba [sic]. Pero es como cuando hablas con tus amigos de fiesta, que a veces hablas de cosas importantes y otras no. No creo que sea para tanto.

Los testimonios obtenidos en las entrevistas son de enorme interés, puesto que aportan un enfoque complementario a los análisis antes realizados. Los resultados de estos últimos apuntaban hacia un cambio significativo en los procesos comunicativos actuales, pero la concepción por parte de los usuarios es mucho menos entusiasta. Ante esta situación, solo caben dos vías de análisis: o bien los sujetos no son conscientes de las dimensiones del proceso en que participan, o esta es una práctica cotidiana, inherente a la lectura de los medios de comunicación de masas. Esta es una cuestión sobre la que conviene reflexionar en mayor profundidad, junto con el resto de resultados de la investigación.

\section{Discusión}

La investigación realizada permite comprobar el grado de desarrollo de la autocomunicación de masas y el peso de los contenidos generados por el usuario (UGC) en la dieta informativa de la ciudadanía actual. A primera vista, los resultados pueden parecer modestos: los entrevistados siguen informándose a través de los medios tradicionales, aunque no los consideren fiables, mientras que consideran las redes sociales y los grupos de Whatsapp prácticas comunicativas secundarias. Sin embargo, la comparación con el programa de Los Manolos y el análisis de la conversación dentro de la comunidad permite establecer unas conclusiones más firmes.

En primer lugar, conviene subrayar la importancia del contexto en que nos encontramos. Por una parte, la ciudadanía está creando espacios mediados al margen de la industria periodística, donde efectivamente se desarrollan procesos de remediación, lectura crítica y creación/cambio de identidades. En el caso de comunidades muy específicas, como el grupo analizado que juega a Comunio, estos cambios afloran incluso en el lenguaje, introduciendo expresiones y estructuras propias. Por otra parte, los medios de comunicación de masas no reaccionan incorporando esta producción, cada vez más legitimada y elaborada, a su discurso, sino que lo modifica ligeramente para vender el mismo contenido bajo un nuevo maquillaje.

Sin embargo, la percepción de los sujetos sobre sus propias prácticas comunicativas obliga a adoptar una posición cauta, quizás más crítica con el enfoque adoptado. En el afán por legitimar los memes, un modo de comunicación legítimo en sí mismo, 
quizás se ha alabado demasiado sus virtudes (carga informativa, lector informado) soslayando su uso mayoritario. No obstante, muchos de los memes encontrados durante la etnografía, como el de Esperanza Aguirre analizado en este trabajo, demuestran su valor como componentes de una comunicación multimedia.

Esta percepción supone una valiosa aportación al debate sobre el periodismo ciudadano y sus promesas; superada la euforia inicial, la percepción sobre las redes sociales y los nuevos medios se ha acercado más a la realidad. Como recoge la investigación, los sujetos participan activamente en las redes sociales y, a pesar de ello (o precisamente debido a ello), no valoran estos espacios como fuentes de democratización de los medios ni, en muchos casos, consideran que la información que se obtiene en ellos sea válida. Podría discutirse ampliamente sobre la tendencia que vincula el uso de estas herramientas y el entusiasmo acerca de sus posibilidades, puesto que estos actores son los más indicados para evaluar los cambios que provocan las redes sociales.

También es destacable que, a pesar de participar activamente en foros y espacios similares, buena parte de los sujetos entrevistados no consideren estas prácticas parte de sus procesos informativos. El análisis conversacional de la comunidad permite comprobar cómo se debate y se contrastan fuentes, un proceso hasta ahora reservado a los profesionales del ámbito y que requiere cierto grado de capacitación. Es un hecho que la ciudadanía participa en el proceso comunicativo de una forma cada vez más elaborada, como demuestran algunos de los vídeos reseñados en el análisis. Frente a esta evolución, el periodismo abraza con esperanza el infoentretenimiento y códigos más cercanos a las producciones informales. Creo que este equilibrio acabará por resolverse en los próximos años a favor de la ciudadanía o de la industria, según actúen unos y otros actores.

Un aspecto importante de la investigación que no se ha resuelto según lo previsto ha sido la vinculación entre la liga de fantasía y la autocomunicación de masas. Entre los sujetos entrevistados, la alta implicación en foros de Comunio no se traduce en una concepción positiva de las redes sociales, ni siquiera implica una presencia activa en las mismas. Resulta llamativo el testimonio del sujeto más activo, presente en seis ligas, que considera que "Whatsapp no sirve para informarse mejor" y opina que "las redes sociales no son mucho mejor" que los medios de comunicación de masas. De todas formas, este aspecto de la investigación era necesario para probar ciertos aspectos de algunos estudios teóricos presentes en el marco teórico.

En resumen, la presente investigación ha tendido puentes entre varias prácticas comunicativas (cambios formales en el periodismo, autocomunicación de masas, memes y parodias humorísticas) para hacer un retrato de la información actual. Caras inseparables de un mismo poliedro, el discurso periodístico y el ciudadano siguen sin encontrar un marco común, creando espacios mediados con identidades, prácticas y semiosferas particulares. Resulta lógico sostener que el futuro de la información deportiva se conformará a partir de todos los elementos reseñados, característicos de la comunicación actual. Detallar el resultado es una tarea más compleja, pero todo parece indicar que su evolución resulta de la mezcla de la incidencia de los consumidores en el ámbito de los productores, sin olvidar el desarrollo de nuevas tecnologías que den un nuevo vuelco a este mundo en continuo movimiento.

La ciudadanía ha demostrado que dispone de recursos y conocimientos necesarios para generar prácticas comunicativas válidas en este contexto, al margen de la industria periodística. Tanto si esta reacciona como si permanece inmóvil, se puede 
afirmar que el futuro de la información no está en manos de una elite sino que es responsabilidad de toda la población.

\section{Bibliografía}

Abril, G. (2013): Cultura visual, de la semiótica a la política. Madrid: Plaza y Valdés.

Aladro, E. (2011): "La teoría de la información ante las nuevas tecnologías de la comunicación". Cuadernos de Información y Comunicación, 16, 83-93

Appadurai, A. (2001): La modernidad desbordada. Buenos Aires: FCE.

Bajtin, M. (1989): Teoría y estética de la novela, Madrid: Taurus.

Baricco, A. (2011): Los bárbaros. Ensayo sobre la mutación, Barcelona: Anagrama.

Barthes, R. (1986): "El mito, hoy” en Mitologías. México: Siglo XXI.

Boczkowski, P. (2013): "Preferencias divergentes de los lectores y de los periodistas en las noticias 'on-line". Cuadernos de Informaci ón y Comunicación, 18, 51-55

Bolter, D. J. y Grusin, R. (2011): "Inmediatez, hipermediación, remediación". Cuadernos de Información y Comunicación, 16, 29-57

Burbules, N. y Callister, T. (2001): Educación: riesgos y promesas de las nuevas tecnologías de la información, Granica: Madrid.

Calsamiglia, H. y Tuson, A. (1999): Las cosas del decir. Manual de análisis del discurso, Barcelona: Ariel.

Castells, M. (2009): Comunicación y poder, Barcelona: Alianza Editorial.

Daubs, M. (2011): Inmediacy and aesthetic remediation in television and digital media: mass media's challenge to the democratization of media production. Ontario: University of Western Ontario.

De Ramón, M. (2011): "La modernización de la radio deportiva en España: el peligro de pasar de la cofradía a la taberna". Cuadernos de periodistas, 23, 72-83.

Hall, Stuart (2004): "Codificación y descodificación en el discurso televisivo", Cuadernos de información y comunicación, 9, 215-236.

Hermida, A. y Thurman, N. (2007): Comments please: How the British news media are struggling with user-generated content. Articulo presentado en el 8th International Symposium on Online Journalism.

IPSOS (2014). Social influence: Marketing's new frontier (en línea). http://corp.crowdtap. com/socialinfluence, recuperado el 20 de agosto de 2014.

Jasper, J. M. (2012): "Las emociones y los movimientos sociales: veinte años de teoría e investigación", Revista latinoamericana de estudios sobre cuerpos, emociones y sociedad, $10,46-66$.

Jönsson, A.M. y Örnebring, H. (2011): "User-generated content and the news. Empowerment of citizens or interactive illusion?", Journalism Practica, 5:2, 127-144

Kress, G. y van Leeuwen, T. (2006): Reading images. The grammar of visual design. Nueva York: Routledge.

Landow, G. (2009): Hipertexto 3.0: la teoría crítica y los nuevos medios en una época de globalización, Barcelona: Paidós.

Lotman, Y. (1996): La semiosfera I. Semiótica de la cultura y el texto. Valencia: Frónesis-Cátedra.

Lovink, G. y Riemens, P. (2011): "Doce tesis sobre WikiLeaks". Cuadernos de Información y Comunicación. 139-147. 
Manovich, L. (2005): El lenguaje de los nuevos medios de comunicación, Barcelona: Paidós. Peñamarín, Cristina (2008): “Hay vida política en el espacio público mediatizado?”, Cuadernos de información y comunicación, 13, 61-78.

Scolari, C. (2008): Hipermediaciones. Elementos para una teoría de la comunicación digital interactiva. Barcelona: Gedisa.

Serazio, M. (2008): "Virtual sports consumption, authentic brotherhood", en Hugenberg, L. W.; Haridakis, P. y Earnheardt, A. C. (eds.), Sports Mania: Essays on Fandom and Media in the 21st Century, Jefferson: MacFarland.

Universidad de Navarra (2014): Reuters Institute Digital News Report 2014: España (en línea) http://www.unav.edu/documents/3786985/0/Reuters-Institute-Digital-News-Report-2014-Espana.pdf, recuperado el 20 de agosto de 2014.

Van Dijk, T. (1990): La noticia como discurso, Barcelona: Paidós. 